\title{
Uso de Jogo Computacional para Auxílio à Alfabetização de Jovens e Adultos do Ciclo I
}

\author{
Luciene Cavalcanti Rodrigues ${ }^{1,2}$, Daynara Minucelli Campos ${ }^{1}$, Susana Cristina \\ Pupio $^{1}$ \\ ${ }^{1}$ Instituto de Federal de Educação, Ciência e Tecnologia de São Paulo (IFSP) \\ Campus Votuporanga \\ Av. Jerônimo Figueira da Costa, 3014 - Pozzobon - Votuporanga, SP - Brasil \\ Grupo de Pesquisa CNPq: Tecnologias e práticas inovadoras aplicadas ao ensino \\ ${ }^{2}$ Faculdade de Tecnologia de São José do Rio Preto (Fatec) \\ Centro Estadual de Educação Tecnológica Paula Souza \\ Rua Fernandópolis, 2510 - Eldorado - S. J. Rio Preto, SP - Brasil \\ prof.lucienedifsp.edu.br, daynaramcampos@gmail.com, \\ susanapupio@gmail.com
}

\begin{abstract}
According to the PNAD data released in September 2013, in Brazil there was an increase of 300,000 illiterate citizens in the period 2011-2012, which is the highest rate in 15 years. Given these data, we note that it is very important that courses for Young and Adult Education (EJA) are provided by brazilian schools, further relying on partnerships that are also aimed at digital inclusion (in partnership with IFSP campus Votuporanga). Within this context, we present our experience with the use of computer games (Alfabetizando 2.0) as an aid to literacy for young and adults, and the tests were conducted with 16 students and two teachers from the regular course, obtained high acceptance rate.
\end{abstract}

Resumo. Segundo dados da PNAD, realizada em 2012 divulgado em setembro de 2013, no Brasil houve um aumento de 300.000 cidadãos analfabetos no periodo de 2011-2012, sendo este o maior índice dos últimos 15 anos. Diante destes dados, nota-se que é de suma importância que cursos de Educação de Jovens e Adultos (EJA) sejam ministrados por escolas de todo o Brasil, ainda mais contando com parcerias que visam também à inclusão digital (parceria com o IFSP campus Votuporanga). Dentro deste contexto, apresenta-se a experiência com o uso de jogos computacionais (Alfabetizando 2.0) como auxilio à alfabetização de jovens e adultos, sendo que os testes foram realizados com 16 alunos e duas professoras do curso regular, obtendo-se alto indice de aceitação.

\section{Introdução}

Segundo Valle (apud Davarpanah et al. (2013)), alfabetização é a assimilação de um sistema complexo, que não acontece por acaso, porque pressupõe o aprendizado de regras combinadas ao longo de vidas, desde a antiguidade. Alfabetização é um processo de participação social, como acontece quando se entra para um time esportivo, em que o progresso de um membro beneficia a todos. 
De acordo com a Pesquisa Nacional por Amostra de Domicílios (PNAD) de 2012 ${ }^{1}$, correspondente aos anos de 2011-2012, indica que o índice de analfabetismo no Brasil sofreu um grande aumento (de 300.000 cidadãos); esse crescimento foi observado predominantemente nas regiões Nordeste e Centro-Oeste, onde a taxa de analfabetismo passou de 16,9\% em 2011 para 17,4\% em 2012. Tais taxas são notadas entre a população que tem 60 anos ou mais, sendo que $24,4 \%$ não sabem ler ou escrever. $\mathrm{Na}$ faixa etária dos 40 aos 59 anos a proporção é de 9,8\% do total; dos 30 aos 39 anos registram-se $5,1 \%$, e dos 25 a 29 anos, $2,8 \%$ são analfabetos .

De acordo com Fonseca et al. (2012), a era digital tem tornado cada vez mais simples o acesso à informação, tudo se fazendo com um rápido "click". As relações humanas, os mecanismos de ensino e aprendizagem, bem como o tipo de comunicação têm transformado os métodos de ensino-aprendizagem. Pierre Levy (2000) menciona que essa transformação deve-se à Cibercultura, visto que a tecnologia domina o cotidiano de jovens e adultos, alterando o modo de vida e a forma de pensar de todos. Nos dias atuais, a cultura da digitalização, a globalização e a virtualização progressiva tornam necessário o acompanhamento das ações da classe docente (Fonseca et al., 2012).

Segundo Fonseca et al.(2012), a educação de hoje pode ser trabalhada em parceria com a tecnologia, tendo em vista a maior eficiência no processo ensino aprendizagem. Freire (1996 apud Fonseca et al., 2012) entende que ensinar é uma especificidade humana que exige segurança, competência profissional e generosidade, além do comprometimento e a compreensão de que a educação é uma forma de intervenção no mundo. Nesse contexto, deve-se considerar também que há uma mudança no papel do aluno, que passa de receptor de informações a construtor do seu conhecimento.

Dentro desse cenário, no qual notadamente se devem aliar tecnologia, educação e esforços para a diminuição do analfabetismo no Brasil, surgem os objetivos gerais deste projeto que visa estudar o ensino andragógico com foco na alfabetização de adultos; desenvolver um jogo lúdico e não infantilizado para auxílio à alfabetização; tornar-se uma ferramenta interativa gratuita para auxílio à alfabetização de jovens de adultos;

\section{Andragogia e Tecnologia Aplicada à Educação}

Segundo Martins (2013) é preciso considerar que a experiência é a fonte mais rica para a aprendizagem de adultos. Estes, por sua vez, são motivados a aprender conforme vivenciam necessidades e interesses que a aprendizagem satisfará em sua vida. $O$ modelo andragógico baseia-se nos seguintes princípios: Necessidade de saber, Autoconceito do aprendiz, Papel das experiências, Prontidão para aprender, Orientação para aprendizagem e Motivação.

Para Carvalho et al. (2008):

Revela-se pouco produtivo iniciar um programa de educação, em especial de alfabetização de jovens e adultos, sem o conhecimento da realidade social da

1 RITTO, C. Depois de 15 anos, taxa de analfabetismo volta a crescer no Brasil. 2013. Disponível em: VEJA.com $<$ http://veja.abril.com.br/blog/reinaldo/geral/depois-de-15-anos-taxa-de-analfabetismo-volta-a-crescer-nobrasil/>. Acesso em: 03 set. 2014. 


\begin{abstract}
comunidade em foco. De fato, muitas propostas pedagógicas falham porque seus realizadores partem de uma visão pessoal da realidade, ou seja, não levam em conta, num mínimo instante, "os homens em situação a quem se dirige seu programa, a não ser como puras incidências de sua ação." (FREIRE, 1987, p. 84). Por isso, ao iniciar o processo de alfabetização, devem-se buscar os temas socialmente e existencialmente significativos para os(as) alunos(as). Pois, quanto melhor o educador conhece seus alunos (sua linguagem, realidade social, necessidades, crenças religiosas, medos, interesses e aspirações) melhores serão suas condições de realizar um bom trabalho pedagógico. Este é um conhecimento que se constrói previamente, ou seja, antes mesmo de iniciar o processo ensino-aprendizagem, assim como ao longo do período das aulas, à medida que nelas os(as) alunos(as) tenham oportunidades de falar de suas vidas, seus gostos, interesses etc.
\end{abstract}

Segundo Martins (2013), para a aprendizagem do público jovem e adulto é necessário o acompanhamento e o direcionamento dos saberes já adquiridos, pois este público já possui vivência extracurricular. É importante que o professor trabalhe saberes que possam auxiliar situações vividas no cotidiano desses alunos, tais como: preenchimento de ficha cadastral de crediário, de locação, de conta bancária, de cartão de crédito; subscrição de envelope, de depósito bancário; leitura e compreensão de extrato bancário ou de outra entidade financeira, lista de compras de supermercado, lista de presentes de natal, entre outros.

Ainda na opinião de Martins(2013), cursos na modalidade EJA podem utilizar o computador como um aliado à alfabetização através de atividades de jogos educativos, produção de textos, de cartas ou de e-mail, análise sobre localização física e virtual por meio do uso de um computador ou de um celular conectado à internet, envio e recebimento de mensagens pelo celular, trabalhando a inclusão digital e suas tecnologias como facilitadoras e também prazerosas. Dessa forma, o professor apresenta a tecnologia a alguns e amplia os conhecimentos de outros, estabelecendo uma troca de saberes que deve ser articulada em sala de aula com alunos EJA.

Segundo Carvalho et al. (2008), a alfabetização e a inclusão digital são ferramentas cruciais para qualquer criança, jovem ou adulto adquirir habilidades essenciais para vencer os desafios do mundo atual. Representa, ainda, um passo indispensável para efetiva participação numa sociedade do conhecimento marcada pela informatização e pela globalização.

Na opinião de Andrade (2012 apud An et al., 2013), as novas tecnologias existentes na sociedade são fatores positivos para o processo de ensino e aprendizagem, evoluindo a forma como a didática pode ser trabalhada. Essa situação favoreceu o surgimento da informática educativa nas escolas, em que diversos jogos digitais foram construídos para colaborar com o processo de ensino e aprendizagem (Godinho,2004 apud An, 2013).

Segundo Paulo Freire (1989 apud An et al., 2013), não é interessante um processo de alfabetização em que haja apenas uma memorização repetitiva dos "ba-bebi-bo-bu", não se podendo minimizar a alfabetização ao ensino puro da palavra, das sílabas e das letras.

Carvalho et al. (2008) concluem em seu trabalho que:

... as vivências revelaram um dado absolutamente interessante: a profusão de possibilidades do uso do software como instrumento potencializador da 
aprendizagem. ... Face aos apelos midiáticos do mundo contemporâneo, a escola tem encontrado cada vez mais dificuldades para motivar os alunos. Com a utilização do computador, observamos que o processo ensinoaprendizagem flui com mais naturalidade e tranquilidade. Sustentamos que isto decorre da unidade orgânica existente entre o contexto familiar dos educandos, marcado pela presença expressiva das mídias digitais e o desenvolvimento do processo ensino-aprendizagem (Carvalho et al, 2008, pág. 228).

Segundo Passerino (apud An et al., 2013), os jogos educativos são criados com a finalidade dupla de entreter e possibilitar a aquisição de conhecimento, encontrando motivação e aptidões que são importantes para participação do indivíduo no meio social.

\section{O Jogo: alfabetizando}

Devido ao fato de que os laboratórios de informática das escolas subsidiadas pelo governo utilizam o sistema operacional Linux, o aplicativo foi desenvolvido em linguagem de programação Java utilizando a IDE NetBeans de forma a tornar-se multiplataforma. Ao se iniciar o aplicativo será apresentada uma interface de apresentação (Figura 1a) e posteriormente será solicitado o nome do aluno (Figura 1b), visando trabalhar a memorização do nome do aluno e apresentar as mensagens personalizadas a partir deste momento.
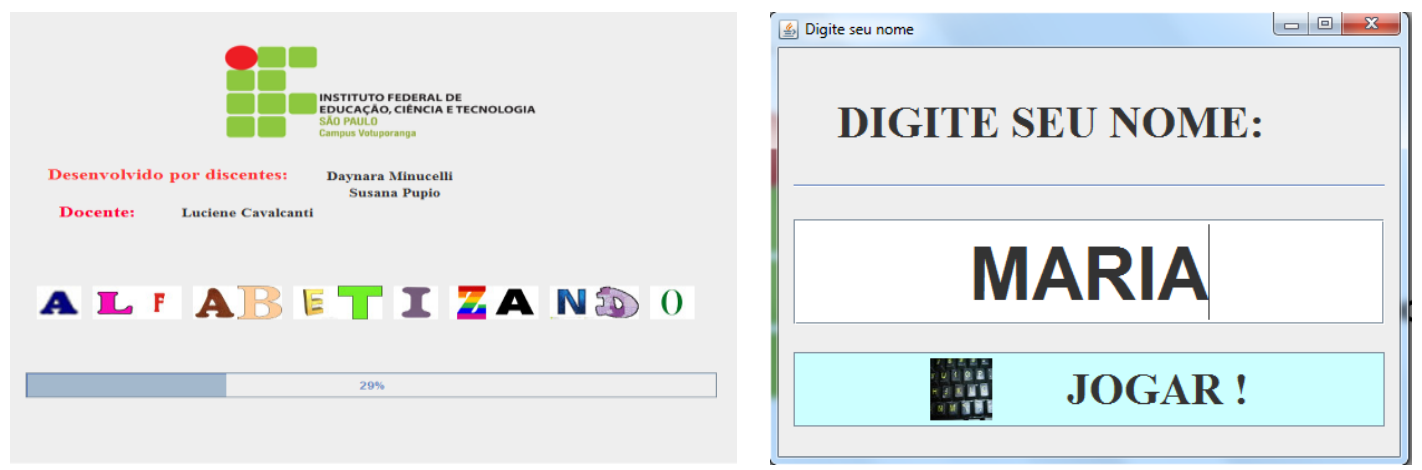
Figura 1 - a) Interface de Inicialização b) Interface para personalização do
software

Do ponto de vista pedagógico, trabalhar com o nome próprio desencadeia aprendizagens significativas, porque o ponto de partida é a identidade do sujeito (Ferreiro e Teberosky, 1999 apud Carvalho et al., 2008, p. 224). O aplicativo seguiu algumas características do software PARTICIPAR descritas por Veneziano et al (2013): uso de letras maiúsculas; fonte Arial de tamanho grande; palavras representadas por fotografias reais; as palavras trabalhadas nos exercícios e nas lições foram selecionadas de forma a serem significativas aos estudantes; interface enxuta e objetiva a fim de não dispersar a atenção do estudante ou confundi-lo.

Após a digitação do nome o aluno poderá escolher entre os jogos disponíveis no aplicativo (Figura 2) que são: Clique nas letras, Digite as Letras e Digite a palavra. 


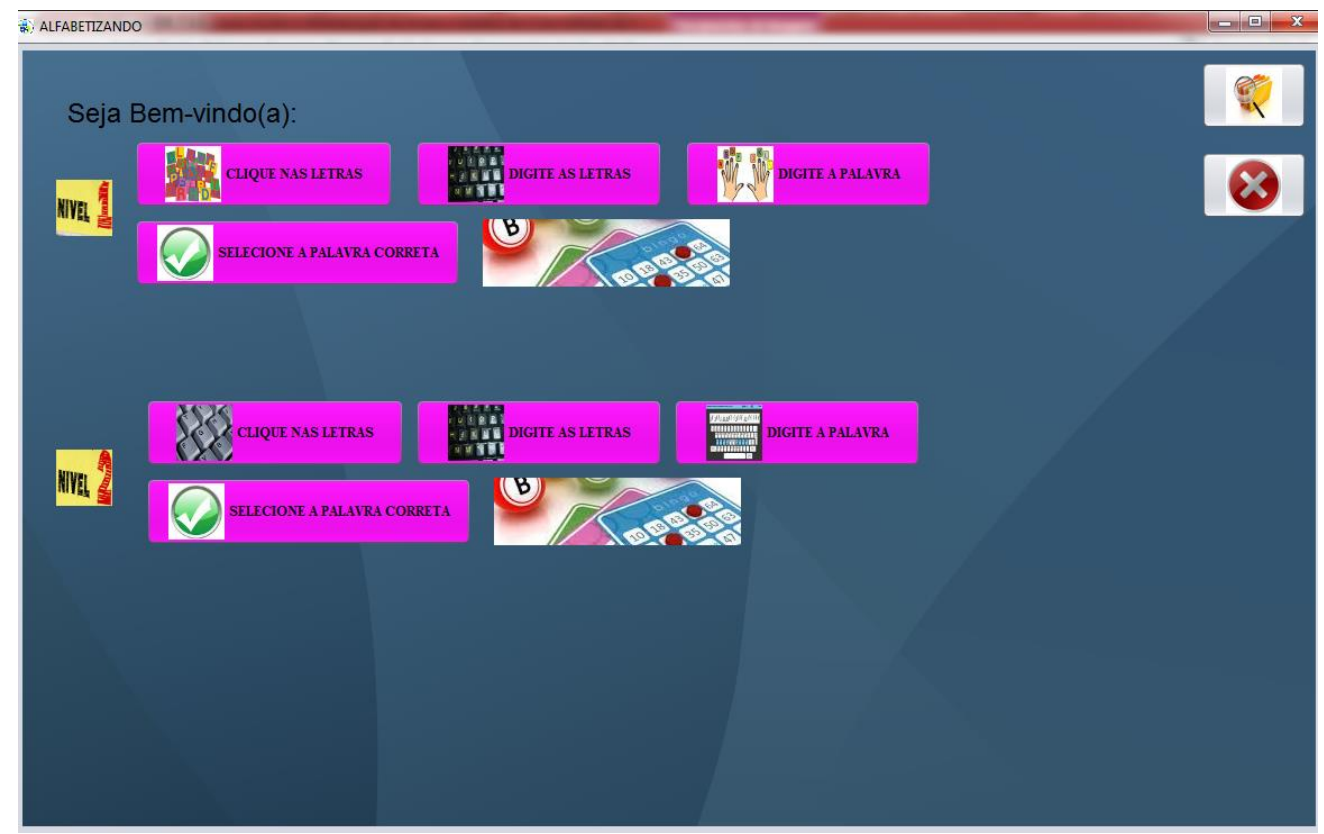

Figura 2 - Interface Principal do Aplicativo

Cada tipo de jogo possui dois níveis de dificuldade; no nível 1 foram separadas 92 palavras mais simples (Figura 3a) e no nível 2 foram separadas 154 palavras mais complexas (Figura 3b).

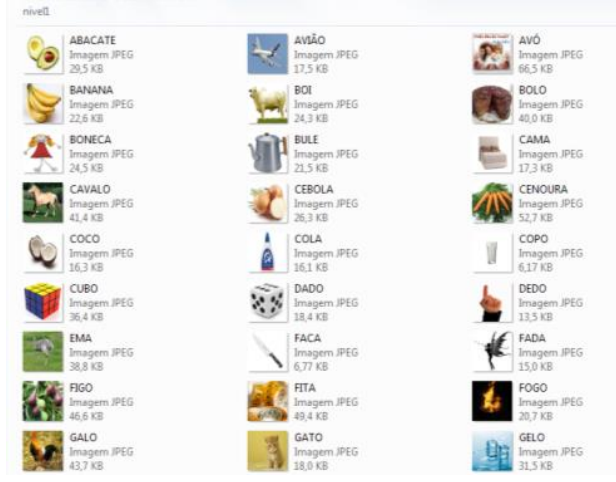

Figura 3 - a) Exemplos de imagens do nível

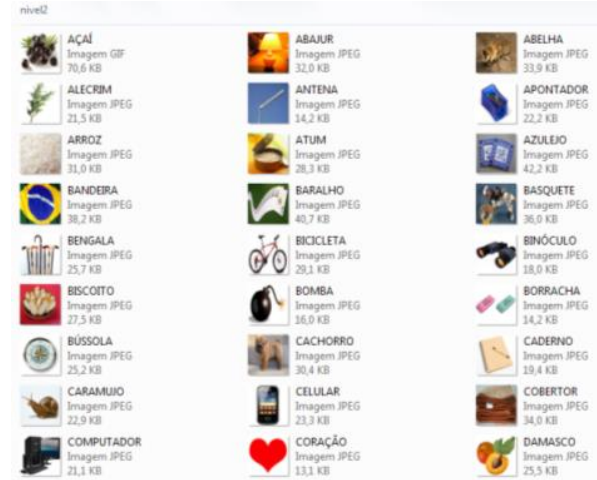

b) Exemplos de imagens do nível 2

Para aplicar maior flexibilidade ao aplicativo, as palavras a serem exibidas podem ser modificadas por qualquer usuário (professor ou aluno), para isso basta separar outras imagens, colocar o nome do arquivo todo em letra maiúscula e da forma que se deseja que apareça no aplicativo e copiá-las para a pasta específica que foi criada na instalação. Após estes procedimentos os jogos farão a adaptação e a exibição dessas palavras automaticamente, sem a necessidade de configurações específicas no software.

Todos os jogos possuem interfaces amigáveis, não infantilizadas e seguem um padrão, de forma que o aprendizado sobre o manuseio de qualquer um dos jogos tornase rápido. As interfaces iniciam-se com a exibição da primeira imagem selecionada na pasta; mostram uma dica de quantas letras devem ser selecionadas; botões para apagar tudo que foi digitado e apagar somente a última letra; dica sonora com o áudio da imagem exibida; contagem do tempo do jogo, dos acertos e erros; e o botão "Ir para o próximo", que fará a correção da palavra, a atualização dos campos de contagem de 
acertos e erros, exibindo uma nova imagem, se a palavra digitada corresponder à imagem exibida ou exibirá uma mensagem de erro.

No Jogo "Clique nas Letras" (Figura 5a) a interface sorteará aleatoriamente 12 letras do alfabeto (inclusive acentuadas) e o usuário deverá selecionar as letras para a formação da palavra com o uso do mouse. Neste Jogo, além de trabalho com a fixação de letras, palavras e auxílio à alfabetização, também se trabalha a coordenação motora e a familiarização com o uso do mouse do computador, focado no desenvolvimento psicomotor do indivíduo, aspectos esses importantíssimos, visto que pessoas com idade mais avançada possuem certa rejeição ao 'novo' e que as articulações e músculos não possuem tanta destreza e habilidade com este tipo de equipamento.

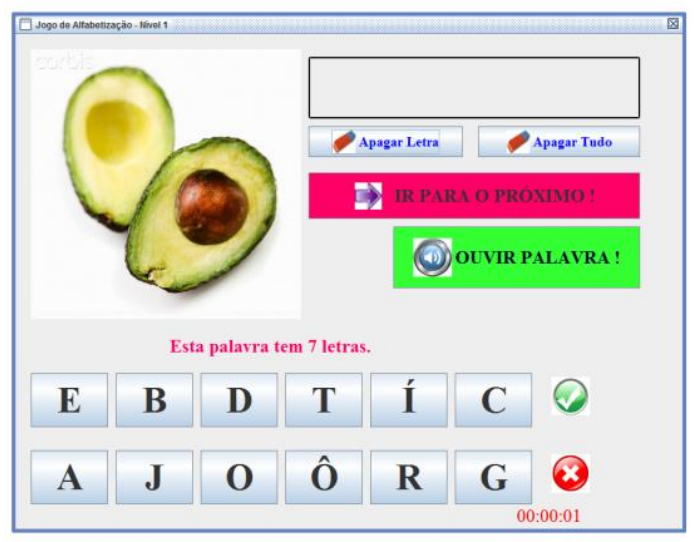

Figura 4 - a) Jogo "Clique nas Letras"

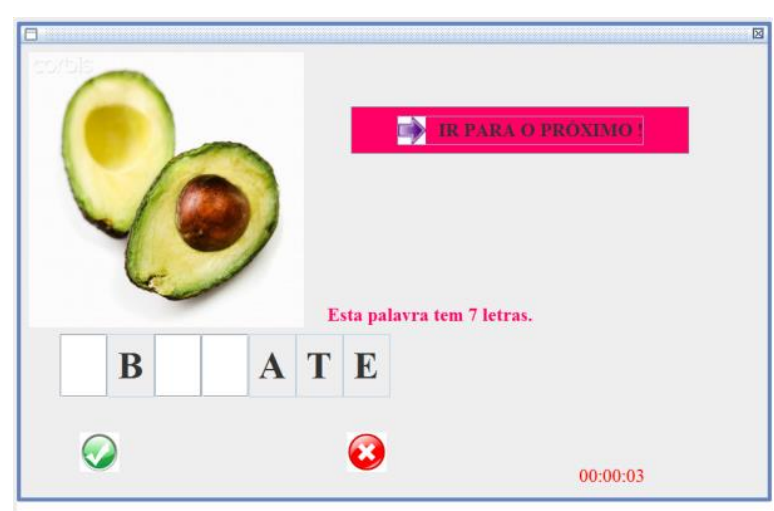

b) Jogo "Digite as Letras"

No Jogo "Digite as Letras" (Figura 5b) serão exibidas as mesmas imagens do jogo anterior de acordo com o nível escolhido, porém esta interface sorteia algumas letras que serão retiradas aleatoriamente da palavra para que o usuário digite no espaço em branco a respectiva letra para a formação da palavra correta. Neste jogo, além do auxílio à alfabetização também ocorre o aprendizado do uso do teclado e do mouse do computador, visto que o usuário deverá clicar no campo em branco e digitar a respectiva letra.

No Jogo "Digite a Palavra" (Figura 6a) serão exibidas as mesmas imagens do jogo anterior de acordo com o nível escolhido, porém agora a interface apresenta apenas um campo para que o usuário digite a respectiva palavra completa.

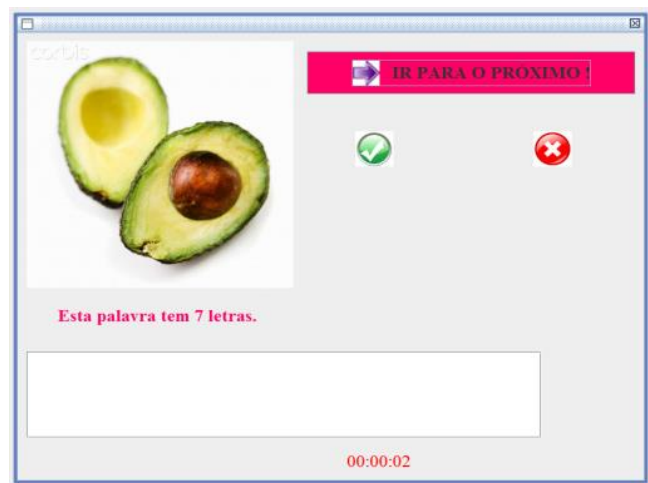

Figura 6 - a) Jogo "Digite a Palavra"

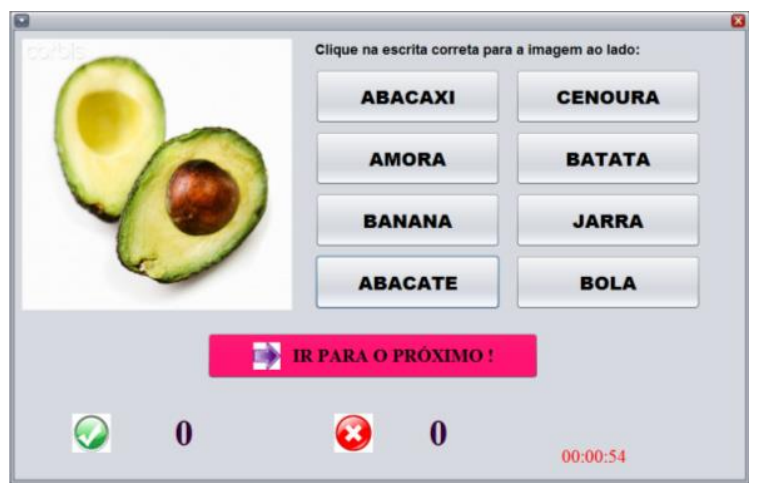

b) Jogo "Selecione a palavra" 
No Jogo "Selecione a Palavra" (Figura 6b) serão exibidas as mesmas imagens do jogo anterior de acordo com o nível escolhido, porém agora a interface apresenta oito palavras diferentes para que o usuário selecione a palavra que corresponde à imagem apresentada.

Ao final de cada um dos jogos será apresentada a mensagem com a quantidade de acertos de cada nível (Figura 7).

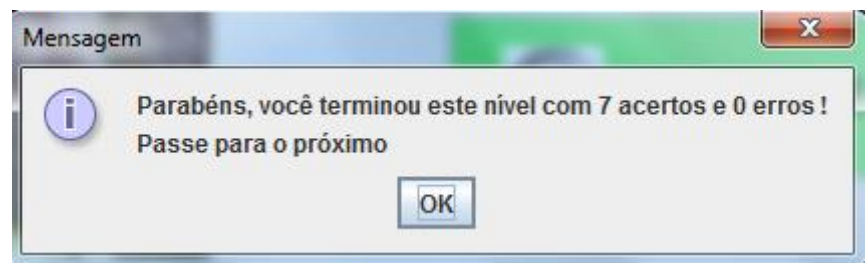

Figura 7 - Encerramento do jogo

Para a versão 2.0 do jogo Alfabetizando foi desenvolvido um jogo de "Bingo", com o intuito de trabalharmos um tipo de jogo que já é muito utilizado por pessoas de maior idade onde ocorre um sorteio de números e cada participante possui uma cartela com diversos números aleatórios. No jogo de Bingo comum (ou Loto), a cada sorteio o participante verifica se o número sorteado encontra-se em sua cartela e marca-o. Ganha quem marcar todos os números de sua cartela.

Neste jogo de "Bingo Digital" uma interface fará o sorteio da imagem (Figura 8a) e cada participante deverá marcar em sua cartela a palavra que representa a imagem sorteada (Figura 8b).

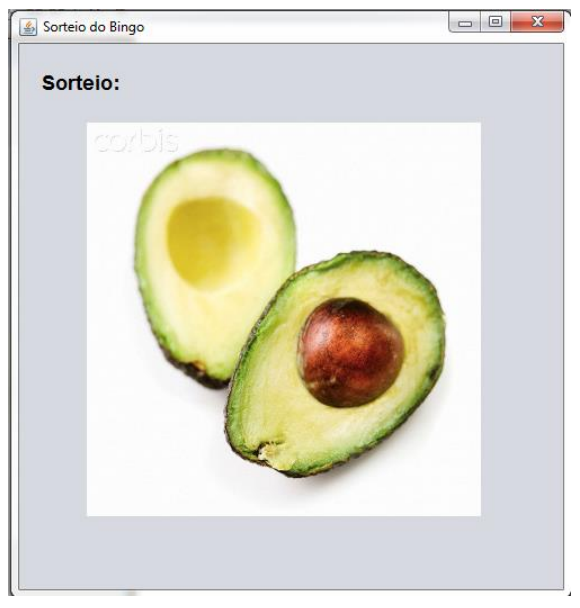

Figura 7 - a) Sorteio das imagens

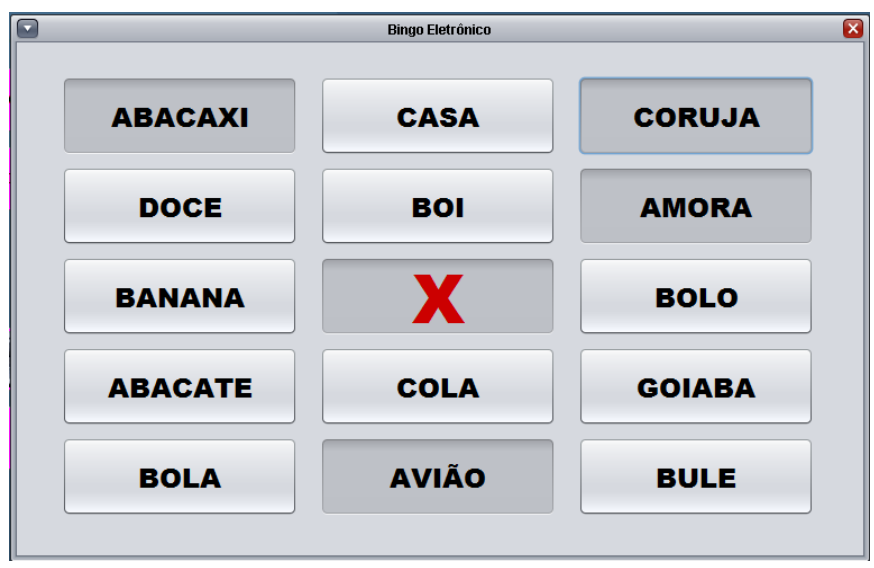

b) Cartela de Marcação do Bingo

O jogo do Bingo pode ser utilizado também sem o uso de vários computadores e das cartelas digitais pois foram confeccionadas cartelas em um arquivo no formato Word de forma que pode-se imprimi-las e distribuí-las entre os alunos e, utilizando-se um projetor ou um monitor de computador/notebook realiza-se o sorteio, tornando-se assim uma atividade que pode ser desenvolvida em sala de aula ou em laboratório de informática. 


\section{Testes e Resultados}

Dentro da turma havia 16 alunas com idade média acima de 50 anos, em cada aula as alunas receberam instruções sobre o funcionamento do jogo a ser utilizado e os testes foram realizados durante várias aulas e em diversos níveis. As Figuras 9a e 9b mostram o laboratório de informática com as alunas utilizando o jogo.
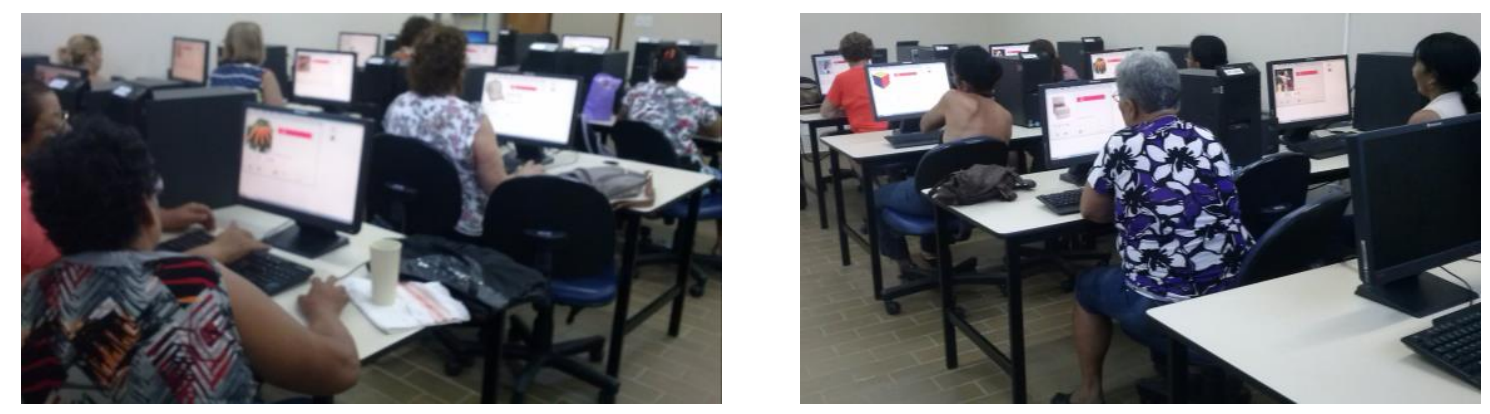

Figura 5 a e b - Alunas utilizando o Jogo

A fim de analisar características como quantidade de acertos e tempo, foi anotada, durante o segundo teste com 13 alunas executando o jogo "Clique nas letras" no nível 2, a quantidade de acertos de cada aluna durante uma hora e meia de aula (Tabela 1).

Tabela 1 - Quantidade de acertos do Jogo "Clique nas letras" no Nível 2

\begin{tabular}{ccc}
\hline & ACERTOS & QUANTIDADE \\
$0-20$ & 1 \\
$21-40$ & 5 \\
$41-60$ & 5 \\
$61-80$ & 1 \\
& $81-100$ & 0 \\
& Acima de 100 & 1 \\
TOTAL: & & 13 \\
\hline
\end{tabular}

Como as alunas já conheciam o jogo, mas era a primeira vez que elas acessavam o nível 2, que possui grau de dificuldade e quantidade de palavras maior, somente 1 aluna conseguiu acertar todas as palavras dentro do tempo especificado. No teste com o mesmo jogo no nível 1, apenas 3 alunas não conseguiram terminar o jogo no tempo especificado.

Outro aspecto analisado durante os testes foi o tempo gasto por cada aluna (Tabela 2) no Jogo "Digite as Letras" no nível 1. Nota-se que o processo de digitação da letra (uso do teclado) em relação ao uso do mouse (Jogo "Clique nas Letras") fez com que o tempo para finalização do jogo fosse menor. 


\section{Tabela 2 - Tempo de Finalização do Jogo "Digite as letras" no Nível 1

\begin{tabular}{cc}
\hline TEMPO & QUANTIDADE \\
$0-20 \mathrm{~min}$ & 3 \\
$21-40 \mathrm{~min}$ & 8 \\
$41-60 \mathrm{~min}$ & 3 \\
1 hora & 2
\end{tabular}

TOTAL DE PESSOAS: $\quad 16$

Além dos testes quantitativos também foram realizadas entrevistas a fim de levantar a percepção dos alunos qualitativamente. Desta forma, o resultado foi que tanto as professoras regulares quanto os alunos citaram a facilidade de uso, a simplicidade da interface e a diversidade das atividades como um bom diferencial em relação ao que se encontra no mercado gratuitamente, não sendo necessário qualquer tipo de treinamento para uso do jogo. Como o jogo de Bingo foi implementado apenas na versão 2.0 do Alfabetizando, não foi possível até o momento a realização de testes com a referida turma.

\section{CONCLUSÃO}

Foram apresentadas neste artigo a problemática da elevação do índice de analfabetismo no Brasil e a necessidade de inclusão digital de jovens e adultos. Na tentativa de aliar forças e fortalecer tanto o processo de alfabetização quanto a inclusão digital, este projeto demonstra o desenvolvimento, a implantação e os testes de jogos computacionais voltados à Educação de Jovens e Adultos.

Para o correto direcionamento do aplicativo foram realizadas várias pesquisas no intuito de encontrar jogos similares que não sejam infantilizados e que possam trabalhar com palavras e atividades do cotidiano dos alunos, mas a maioria do que foi encontrado de forma gratuita era voltada para o público infantil. Uma ferramenta interessante foi publicada por Carvalho et al (2008): ela utiliza o método Paulo Freire e conta com os módulos COMEÇAR (10 atividades) e LER (15 atividades) dentro de um ambiente lúdico e intuitivo.

Seguindo-se então os conceitos andragógicos e com a participação das professoras do ensino regular, foi possível a separação de palavras do cotidiano que eram trabalhadas em sala de aula convencional para a formação dos jogos computacionais, tomando-se sempre o cuidado de exibir imagens reais (fotos) e não desenhos.

Os testes foram realizados em várias aulas, de forma que todos os jogos puderam ser acessados por todas as alunas e professoras. A cada aula eram verificados itens tais como facilidade de uso, tempo gasto, quantidade de acertos e erros do jogo. De acordo com as entrevistas realizadas com as alunas e com as professoras depois de realizadas as correções, a interface ficou amigável e contribuiu para que o tempo gasto para percorrer todas as imagens, ou seja, para a conclusão de cada fase aumentasse gradativamente, conforme demonstrado na Tabela 2. 
Na versão 2.0 o Alfabetizando possui um protótipo totalmente online do jogo do "Bingo", na qual cada aluna receberá uma "cartela virtual" com 25 palavras em seu computador e o aplicativo do professor fará o sorteio aleatório das imagens; e uma versão manual, na qual cada aluna receberá uma cartela impressa também com 25 palavras, e através de um projetor o professor poderá fazer o sorteio aleatório das imagens. Para trabalhos futuros já estão sendo desenvolvidos módulos para a separação de sílabas, completar frases, números e cálculos matemáticos, todos voltados para o cotidiano dos adultos, também serão realizados testes de usabilidade para proporcionar melhorias na interface do jogo.

O software foi disponibilizado gratuitamente para download através do site www.4shared.com e já estão sendo analisadas formas de cadastro no Banco Internacional de Objetos Educativos do MEC, juntamente com o tutorial de instalação e uso que já foi desenvolvido.

\section{REFERÊNCIAS}

AN, D. Y. et al. Digita - um Jogo Educativo de Apoio ao Processo de Alfabetização Infantil. II Congresso Brasileiro de Informática na Educação (CBIE 2013) e do XXIV Simpósio Brasileiro de Informática na Educação (SBIE 2013). p. 154 - 163, 2013. DOI: 10.5753/CBIE.SBIE.2013.154.

CARVAlHO, M. et al. Desenvolvimento de Software Para Alfabetização de Adultos Baseado em Princípios Freirianos. XIX Simpósio Brasileiro de Informática na Educação (SBIE 2008).

DAVARPANAH, M. et al. Educação Digital: A Tecnologia a favor da Inclusão. (Valle, Mattos C Costa (ORGs). 2013. Disponível em: $<$ http://books.google.com.br/books?hl=pt$\mathrm{BR} \& \mathrm{lr}=\& \mathrm{id}=\mathrm{PGk} 3 \mathrm{AgAAQBAJ} \& \mathrm{oi}=\mathrm{fnd} \& \mathrm{pg}=\mathrm{PA} 122 \& \mathrm{dq}=$ alfabetiza $\% \mathrm{C} 3 \% \mathrm{~A} 7 \% \mathrm{C} 3$ $\%$ A3o\%2Bcomputador\%2Badulto\&ots=1 VbDcLY6Av\&sig=hGJz2eoXw7gn4sFL4r 0k18Ab5gs\#v=onepage \&q\&f=false $>$. Acesso em: 10 dez. 2013.

FONSECA, E. S. et al. Aplicação de Ambiente Virtual de Aprendizagem como Auxílio ao Ensino Presencial de Processamento Digital de Sinais e Wavelets. Sinergia, São Paulo, v. 13, n. 2, p. 143-152, maio/ago. 2012.

LEVY, P. Cibercultura. 2. ed. São Paulo: Ed. 34, 2000.

MARTINS, R. M. K. Pedagogia e andragogia na construção da educação de jovens e adultos. Rev. Ed. Popular, Uberlândia, v. 12, n. 1, p. 143-153, jan./jun. 2013.

VENEZIANO, W. H. et al. Programa Participar: Software Educacional de Apoio à Alfabetização de Jovens e Adultos com Deficiência Intelectual. Anais do II Congresso Brasileiro de Informática na Educação (CBIE 2013) e do XXIV Simpósio Brasileiro de Informática na Educação (SBIE 2013). DOI: 10.5753/CB 477 IE.SBIE.2013.477. 